Mubai Journal
Dubai Med J 2019;2:134-140

DOI: $10.1159 / 000503383$
Received: May 20, 2019

Accepted: September 16, 2019

Published online: September 27, 2019

\title{
Occlusion of the Main Pancreatic Duct as a Method to Avoid a Pancreatojejunal Anastomosis: Metabolic Consequences
}

\author{
Karina Patiño-Diaz ${ }^{a}$ Esmeralda Mexicano ${ }^{a}$ Neydel Vergara $^{a}$ \\ Celso Contreras ${ }^{a}$ Enrique Sanchez-Valdivieso ${ }^{a}$, b

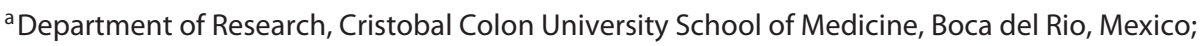 \\ ${ }^{b}$ Department of Surgery, Hospital de Alta Especialidad, Veracruz City, Mexico
}

\section{Keywords}

Pancreatic duct · Ligation - Metabolic profile · Animal model

\begin{abstract}
Introduction: The poor prognosis seen after the Whipple procedure greatly depends on leaks from pancreatic-duodenal anastomosis. Objective: To evaluate ligation of the pancreatic duct without reconstruction of the gastrointestinal tract continuity to prevent pancreatic postoperative fistula occurrence and to reduce surgical time. Methods: An experimental study was carried out on New Zealand adult rabbits who underwent pancreatic duct ligation without pancreatic-duodenal anastomosis. Pancreatic enzyme was administered orally to one operated group; another group of animals was operated on and monitored without enzyme replacement. Results: The groups were compared, and variations in weight and metabolic profiles were assessed. No significant differences were found between both operated groups in terms of postoperative mortality or reoperations. Discussion/Conclusion: The morbidity associated with pan-
\end{abstract}

\begin{tabular}{ll}
\hline KARGER & $\begin{array}{l}\text { ( ) } 2019 \text { The Author(s) } \\
\text { Published by S. Karger AG, Basel Openger }\end{array}$ \\
E-Mail karger@karger.com & $\begin{array}{l}\text { This article is licensed under the Creative Commons Attribution- } \\
\text { NonCommercial-NoDerivatives 4.0 International License (CC BY- } \\
\text { www.karger.com/dmj }\end{array}$ \\
& $\begin{array}{l}\text { NC-ND) (http://www.karger.com/Services/OpenAccessLicense). } \\
\text { Usage and distribution for commercial purposes as well as any dis- } \\
\text { tribution of modified material requires written permission. }\end{array}$
\end{tabular}

creatic duct ligation is low, the procedure is well tolerated, and endocrine insufficiency does not seem to be a problem in the animal model.

(c) 2019 The Author(s)

Published by S. Karger AG, Basel

\section{Introduction}

Pancreatic cancer (PC) is the fourth leading cause of cancer-related death worldwide [1] with a survival rate of $<3 \%$ of the patients 5 years after the initial diagnosis [2, $3]$. Most of the cases correspond to ductal adenocarcinoma (85-90\%) [4]. The mean survival time for unresectable disease is 8 months and for metastatic disease only 10 weeks [5].

For resectable tumors, surgery offers the greatest benefits regarding survival; however, only $10-20 \%$ of the patients will be candidates for resection with curative attempt [6]. Of these, the morbidity of the procedure will affect the quality of life and even cause mortality in 5\% in 
the best series [7]. Pancreatoduodenectomy (PD) [8], reported in 1935 by Whipple et al. [9], has been constantly modified until the standard 1-stage procedure was developed in the 1960s. Traverso and Longmire [10] developed the current PD technique in 1978.

Reconstruction after the PD is done by means of a pancreatic enteric anastomosis (PEA). Even when mortality has fallen to $5 \%$, morbidity remains elevated (30-50\%) [2]. The poor outcome of patients after the Whipple procedure greatly depends on PEA leaks. Pancreatic postoperative fistulae (PPF) are the main cause of morbidity and mortality after pancreas resection and restoration of continuity [3].

A number of surgical techniques have been developed in order to reduce the incidence of PPF, but none has proven to solve the problem mainly due to the lytic effects of pancreatic enzymes on the PEA. Therefore, PEA is still considered the Achilles heel of the procedure [11].

The importance of PPF rests in the fact that, in addition to being a potential threat to life, it causes longer hospitalization and higher costs. Therefore, some authors have advocated simply for ligation of the pancreatic duct (LPD) without reconstruction of continuity of the gastrointestinal tract as a method to prevent PPF. In 1952, Brunschwig [12] reported 3 LPD cases and all of them without PPF development. Goldsmith et al. [13] compared PPF development between 45 patients who underwent LPD and 34 patients treated with anastomosis to the jejunum and found no differences. It has been reported that LPD may cause endocrine pancreas malfunction and diabetes, suggesting that gastrointestinal continuity should be restored. [14]. The aim of this study was to evaluate LPD as a method to prevent PPF and ensuing complications and to decrease surgical time.

\section{Materials and Methods}

This experimental study was carried out on New Zealand adult male rabbits (Oryctolagus cuniculus) that underwent section and occlusion of the pancreatic conduit (without pancreatic-duodenal anastomosis). The study was done in the Experimental Surgical Unit of the Cristobal Colon University School of Medicine with previous authorization by the Institutional Committee of Bioethics. All the procedures were done with strict adherence to the Mexican official norms of technical specifications for experimentation on laboratory animals (NOM 062-ZOO-1999). The animals remained lodged in individual cages with commercial food and water administered ad libitum by a veterinarian.

The administered drugs were: ketamine (Anesket, $100 \mathrm{mg} / \mathrm{mL}$ solution for injection), xylazine (TranquiVed, VEDCO, $2 \mathrm{mg} / \mathrm{mL}$ solution), and sodium pentobarbital (Penta-Hypnol, Vetermex
Animal Health, $2 \mathrm{mg} / \mathrm{mL}$ solution). Sutures used were: black silk (Atramat 3-0); polyglycolic acid (Vicryl ${ }^{\mathrm{TM}}$ 2-0), 0.5 circle needle; and nylon (Dermalón $\left.{ }^{\mathrm{TM}} 3-0\right), 0.5$ circle needle. For the replacement of pancreatic enzymes, we used pancreatin (Pankreoflat ${ }^{\circledR}$ tablets containing pancreatin, amylase 6,000 U, lipase 6,000 U, and protease $400 \mathrm{U}$; Takeda Laboratory ).

\section{Procedure}

The animals remained in observation for 10 days before the surgical procedure. The day before surgery, the veterinarian corroborated the animal's suitable state of health. Peripheral blood was then extracted for preoperative studies, including blood glucose, clotting time (APTT, prothrombin time), lipid profile, and blood cell counts. With the abdominal area previously shaved, general anesthesia was administered using a combination of ketamine (dose $35 \mathrm{mg} / \mathrm{kg}$ ) and xylazine (dose $5 \mathrm{mg} / \mathrm{kg}$ ) in the same syringe intramuscularly in the posterior region of the thigh with a 23-G needle, achieving an anesthesia time of 30-45 min per dose.

\section{Section of the Pancreatic Duct}

A midline laparotomy was performed and the pancreatic duct was located. The point of LPD was selected according to the anatomical base of the pancreas drainage in the rabbit. A plane was developed through the mesentery as soon as the conduit was identified and isolated by blunt dissection. An occlusion point was chosen $0.1-0.3 \mathrm{~cm}$ from the entrance of the pancreatic duct into the duodenum, clamped, and sectioned through this window (Fig. 1). The stump was then ligated and the pancreas left without anastomosis to the intestine; LPD was done manually with silk 3-0. During the whole procedure, the cavity was irrigated with saline $(0.9 \%$ $\mathrm{NaCl}$ solution); we then proceeded to close the abdominal wall layers. Animals recovered from the anesthetic effects, and they were offered routine postoperative care including food and water ad libitum. All the operations were done by the same author (E.S.-V.).

\section{Postoperative Course}

After recovery, the animals were randomized to pancreatic enzyme supplementation or not; exogenous pancreatic enzyme was orally administered to a group of 6 operated animals on a daily basis (previous grinding of half a tablet mixed in the food); the second group of 6 operated cases did not received pancreatic enzyme supplementation. Control samples were taken 2-4 months postoperatively including their metabolic profile.

Pancreatic fistulae were defined as drainage of $>200 \mathrm{~mL}$ of pancreatic fluid [15] and/or leakage of pancreatic fluid from the surgical wound lasting $>14$ days after operation in accordance with the enzyme concentration in the fluid (lipase concentration 3 times higher) [16].

Animals were followed up for 4 months postoperatively and daily supervised by the veterinarian. They were evaluated during and at the end of this time period with respect to possible complications. Survival time, body weight, and health status or complications of group members were recorded; the overall operative morbidity, as well as the mortality, and the evaluation of reoperation were recorded in accordance with the Clavien classification at the 30-day follow-up [17, 18]. Clavien grade I and II complications were considered to be minor, while Clavien complications of grade III or more were considered to be major complications. The control nonoperated group of animals (negative control; $n=6$ ) was also observed for the same time as both treated groups. Likewise, 


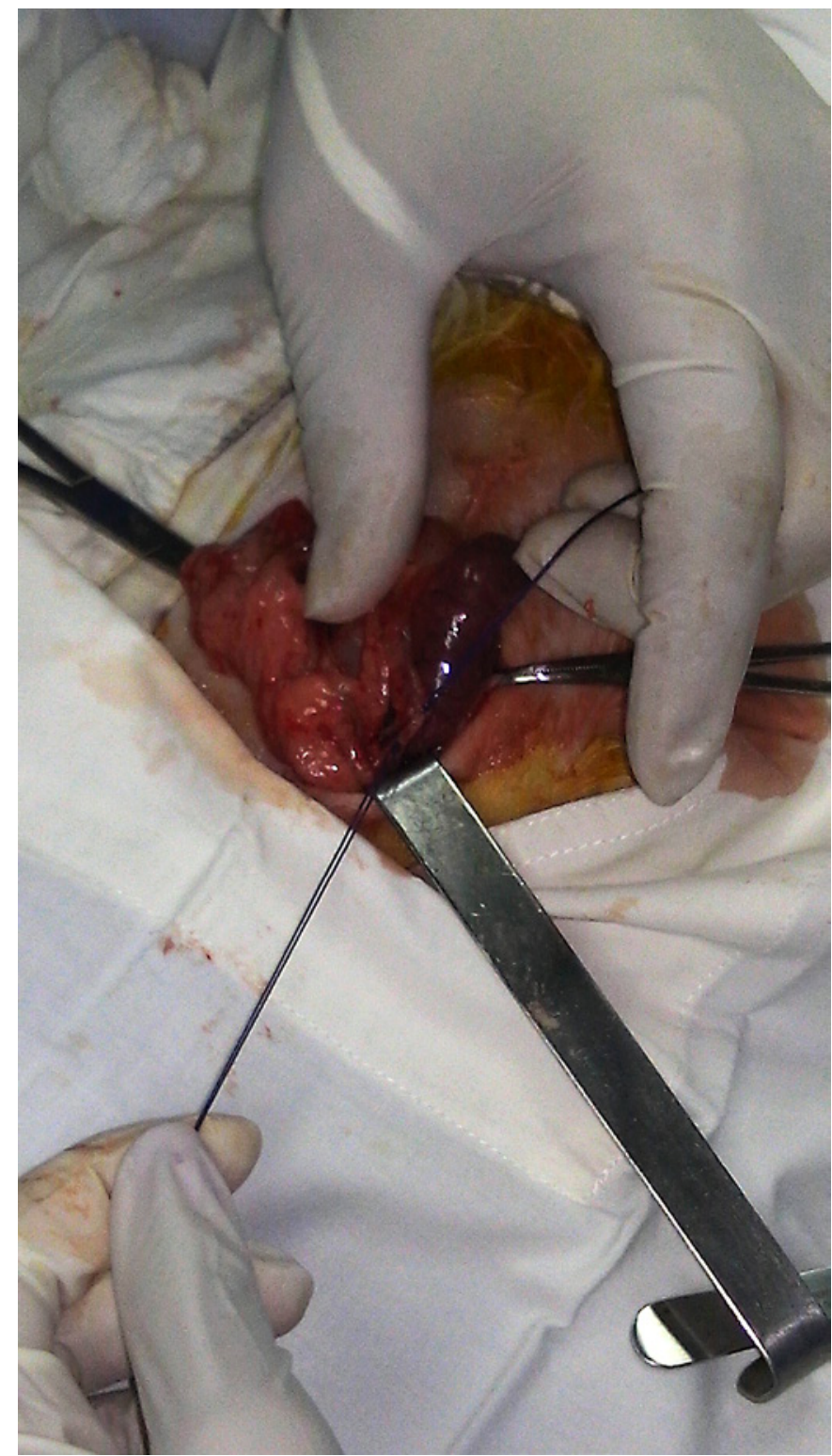

Fig. 1. Photograph showing the doubly-bound main pancreatic duct immediately before being cut.

they underwent the corresponding studies: glycemia level, clotting time (APTT, prothrombin time), lipid profile, and blood cell counts.

\section{Examination at Autopsy}

After venous blood sampling 4 months postoperatively, the animals were submitted to euthanasia. The rabbits underwent euthanasia by using general anesthesia with xylazine $2 \mathrm{mg} / \mathrm{kg}$ and ketamine $35 \mathrm{mg} / \mathrm{kg}$ administered intramuscularly. As soon as the appropriate sedation was achieved, a sodium pentobarbital overdose $(25 \mathrm{mg} / \mathrm{kg})$ was administered by intracardiac injection.

During autopsy, attention was given to the following situations: location and description of adhesions, intra-abdominal fluid collec-
Table 1. Postoperative complications

\begin{tabular}{|c|c|c|c|c|c|}
\hline \multirow[t]{2}{*}{ Complications } & \multicolumn{2}{|c|}{$\begin{array}{l}\text { Group } 1 \\
(n=6)\end{array}$} & \multicolumn{2}{|c|}{$\begin{array}{l}\text { Group } 2 \\
(n=6)\end{array}$} & \multirow{2}{*}{$\begin{array}{l}p \\
\text { (Fisher } \\
\text { exact } \\
\text { test) }\end{array}$} \\
\hline & $n$ & $\%$ & $n$ & $\%$ & \\
\hline Death & 1 & 16.6 & 1 & 16.6 & 1.0000 \\
\hline \multicolumn{6}{|l|}{ Hemorrhage } \\
\hline Free intra-abdominal blood & 0 & 0 & 0 & 0 & \\
\hline Gastrointestinal bleeding & 0 & 0 & 0 & 0 & \\
\hline Both & 0 & 0 & 1 & 16.6 & 1.0000 \\
\hline Constipation & 0 & 0 & 1 & 16.6 & 1.0000 \\
\hline Diarrhea & 0 & 0 & 0 & 0 & \\
\hline Anorexia & 1 & 16.6 & 3 & 50 & 0.5455 \\
\hline Pancreatic fistula & 0 & 0 & 0 & 0 & \\
\hline Acute pancreatitis & 0 & 0 & 0 & 0 & \\
\hline Intra-abdominal fluid collection & 0 & 0 & 0 & 0 & \\
\hline Infection & 0 & 0 & 0 & 0 & \\
\hline No infection & 6 & 100 & 6 & 100 & 1.0000 \\
\hline Biliary/digestive leakage & 0 & 0 & 0 & 0 & \\
\hline
\end{tabular}

tion, or macroscopic evidence of pancreatitis, and signs of infection or hemorrhage. The pancreas was dissected and examined carefully. Liver samples were also obtained at that time. Liver and pancreas were cut and fixed with $10 \%$ buffered formalin solution overnight and embedded in paraffin by the institutional histology core laboratory. Sections cut from each paraffin block were stained with hematoxylin and eosin following standard protocols and observed under a light microscope. Slices of the pancreas and liver were processed for routine paraffin embedding. Unstained $5-\mathrm{mm}$ sections were cut from paraffin blocks, and slides were deparaffinized and stained with PAS (periodic-acid Schiff) by routine techniques.

\section{Analysis}

The results were recorded in Excel ${ }^{\circledR}$; surgical time, initial and final weight, mortality, hemorrhage, constipation, anorexia, complications, blood and lipid profile reports, and pathology were included. The information was processed as mean (SD) for the continuous variables and numbers (\%) of study subjects for categorical variables.

Statistical analysis was done using GraphPad Prism (version 5.0b; GraphPad Software Inc., San Diego, CA, USA). The basal characteristics were compared in both treatment groups using the unpaired two-tailed $t$ test for continuous variables and $2 \times 2$ contingency table risk analysis for categorical variables. To analyze serial determinations of the laboratory tests looking for statistical differences, Student $t$ test and one-way ANOVA were used. Values of $p<0.05$ were considered to be statistically significant.

\section{Results}

Eighteen New Zealand male rabbits (4-6 months of age) were included. Operated animals $(n=12)$ had an initial weight of $3.3 \pm 0.474 \mathrm{~kg}$ (range $2.3-3.9 \mathrm{~kg}$ ). The non- 

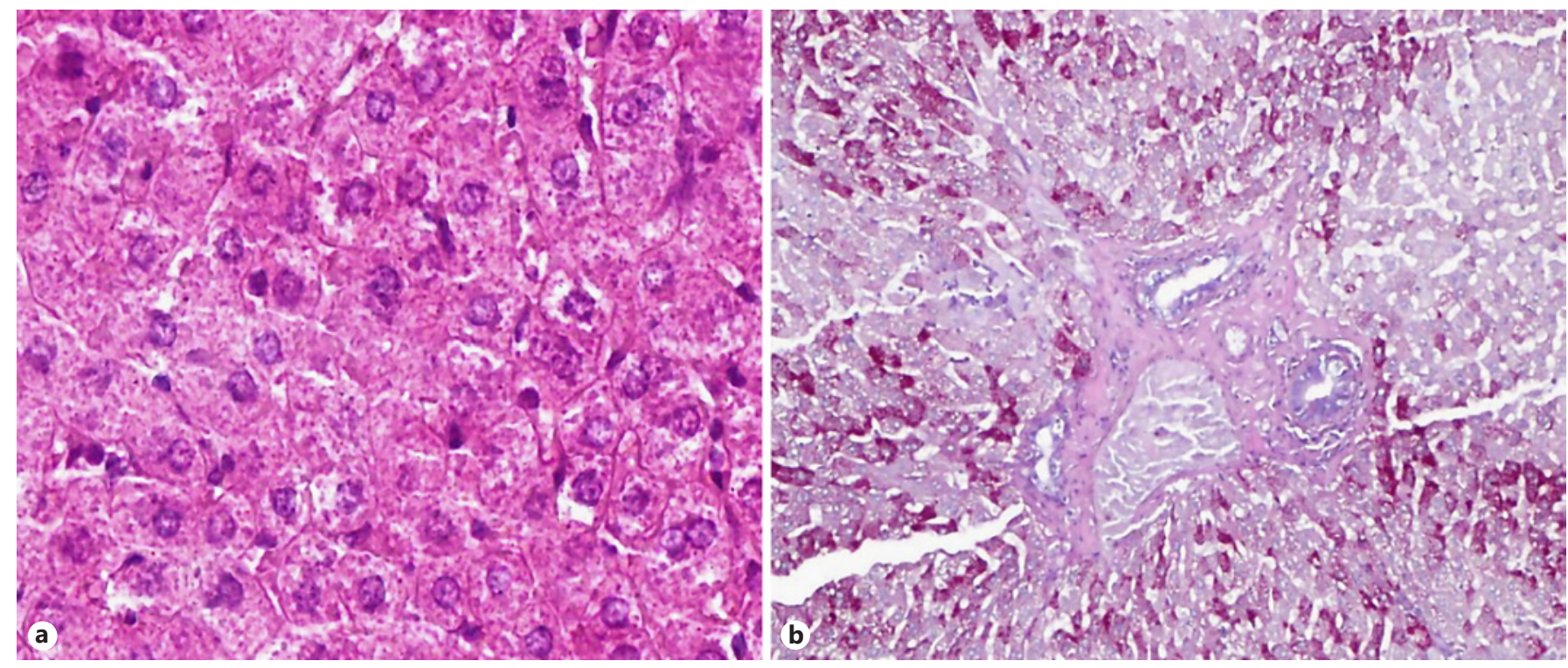

Fig. 2. a Photomicrograph of the exocrine pancreas section obtained from a male operated rabbit showing scarce fibrosis and inflammation; acinar atrophy or islet abnormalities were not observed. $\mathbf{b}$ Photomicrograph of a liver sample showing neither inflammation, stasis, nor atrophy.

operated control group $(n=6)$ had an initial weight of $3.8 \pm 0.641 \mathrm{~kg}$ (range $2.7-4.5 \mathrm{~kg}$ ). Six operated animals received supplementary treatment with pancreatin (group 1 ); they had an initial weight of $3.5 \pm 0.323 \mathrm{~kg}$ (range $3.1-$ $3.9 \mathrm{~kg}$ ), while those without supplementary treatment with pancreatin (group 2) had an initial weight of $3.1 \pm$ $0.538 \mathrm{~kg}$ (range $2.3-3.8 \mathrm{~kg}$ ), being a nonsignificant difference between both groups (Student $t$ test, $p=0.1418$ ).

The mean surgical time was $35.4 \pm 5.4 \mathrm{~min}$. The surgical time was not significantly different between the animals with $(36.7 \pm 5.2 \mathrm{~min})$ or without $(34.2 \pm 5.8 \mathrm{~min})$ pancreatic enzyme supplement. There were 2 operative deaths (16.6\%), 1 in group 1 due to intestinal obstruction and another in group 2 due to intra-abdominal hemorrhage. All the remaining animals recovered well from the procedure. No animal underwent reoperation or percutaneous drainage for complications. There were nonsignificant differences between both groups in terms of postoperative mortality or re-operations. Complications are listed in Table 1.

There were fewer animals with complications in the group of LPD plus pancreatin that in the control LPD group without pancreatin (16.6 and 66.6\%, respectively), but the difference was not statistically significant (Table 1). No animal had hyperglycemia at the 4-month follow-up. No increase in stool fat was evident.

None had macroscopic evidence of pancreatitis during necropsy. Overall, at microscopic examination, the pancreas did not show significant histological alterations (Fig. 2a); the pancreatic duct occasionally showed mild fibrosis, ischemic necrosis in the mucosa, or even marked chronic transmural inflammation with acute hemorrhage in 1 animal from group 1; no significant histological alterations were observed in the duodenum except in 1 animal from group 2, which had mild focal chronic inflammation and focal fibrosis in the muscle layer; the liver showed occasionally mild portal hepatitis, and there was neither periductal fibrosis nor cholestasis (Fig. 2b).

\section{Discussion/Conclusion}

The possibility of complications after pancreatic-jejunal anastomosis (PJA) is elevated. A major cause is leakage of the surgical anastomosis [19] due to the digestive capacity induced by pancreatic enzyme activation. PPF then constitutes the most frequent complication associated with the $\mathrm{PD}$ and even accounts for a high percentage of perioperative deaths.

The absence of an anastomosis in the pancreatic remnant may decrease the expected postoperative complication rate. Even a fistula from the pancreatic stump has a lower morbidity-mortality rate than from PJA since there is no defect in the small intestine, and, likewise, there is no pancreatic enzyme activation [14]. 
The results described here are highly similar to those described by Nomikos et al. [20], who, in order to avoid the PJA-related morbidity and mortality after PD, used LPD for pancreatic stump management after the Whipple procedure. They studied a series of 9 consecutive patients (8 with PC and 1 with chronic pancreatitis). Pancreatic fistulae developed in 4 of their patients, which spontaneously resolved at 14-58 days (mean 35.4 days) [20]. They reported 2 postoperative deaths due to causes not related to PD. Remarkably, none of their patients developed diabetes mellitus (DM) or other postoperative complications, i.e., acute pancreatitis or pancreatic insufficiency. These authors concluded that LPD can lead to a controlled pancreatic fistula, with evanescence of the inactive contents over the course of time without causing any metabolic complication; therefore, they recommended LPD as a simple, fast, and safe alternative to PJA [20].

On the other hand, in 1977, Nakase et al. [19] reported 824 cases with $14 \%$ dehiscence of the PJA. Marczell and Stierer [21] treated 10 patients with LPD without occlusion with fibrin and reported fistulas in $20 \%$, and $20 \%$ of deaths due to necrotizing pancreatitis, compared to PJA ( $4.54 \%$ of fistulas and $2.27 \%$ of deaths secondary to necrotizing pancreatitis).

An important factor in PPF prevention in patients with $\mathrm{PD}$ is the technical skill, precision, and fine management required for PJA construction. These factors could be of highest importance during the learning curve of young surgeons; therefore, even with the most insignificant doubt from surgeon, it is possible to choose a simple LPD procedure. In the case of severe trauma in the pancreatic region, LPD is a reasonable option in severely injured patients. Gentilello et al. [22] investigated the use of LPD during a Whipple procedure for trauma. They treated 13 cases with the Whipple procedure for trauma and LPD and compared it to PJA. Overall mortality was $53.8 \%$. Pancreatitis presented in 3 cases (23.1\%) as the cause of death. Pancreatic fistulae occurred in $50 \%$ of patients who survived $\geq 2$ days after LPD. No long-term survivor developed DM. Malabsorption was present in $50 \%$ of longterm survivors. Differences in mortality and morbidity were not statistically significant between LPD and PJA groups. The authors mentioned that the LPD survival rate of $46.2 \%$ justifies its consideration as an option in unstable patients who are unable to tolerate a longer operation and/or a reconstructive procedure [22].

In a study of LPD in dogs [23], endocrine insufficiency was observed in 10 (67\%) of 15 animals 45 and 222 days postoperatively evaluated by the levels of fasting glycemia, circulating plasma levels of insulin, and intravenous glucose tolerance test. These authors suggested that the severe fibrotic regeneration seen in exocrine tissue might lead to secondary endocrine malfunction [23]. It has been reported that LPD is usually followed by interstitial fibrosis with subsequent high-degree sclerosis of the pancreatic exocrine parenchyma, which starts already 2 days postoperatively concomitant with alterations in endocrine function [24].

Soltani et al. [25] found insulin-positive cells in the ductal lumen among the ductal cytokeratin-positive epithelium spreading towards the surrounding conjunctive tissues, providing evidence of a ductal origin for the islet neogenesis. It has been suggested that the severe fibrotic degeneration of the exocrine pancreatic tissue secondary to LPD might progress to endocrine dysfunction [23], which was not evident in our study animals after an observation period of 120 days. Hultquist et al. [26] stated that the regenerative capacity of the atrophic part of the pancreas diminishes with time after LPD, at least regarding islet cells; therefore, it seems improbable that our animals would have developed endocrine pancreatic failure after this follow-up period.

The disadvantage of LPD without anastomosis is the definitive loss of the pancreatic exocrine function and a need for oral treatment with pancreatic enzymes. On the other hand, pancreatin causes movilization of $4.9 \mu \mathrm{Eq}$ fatty acids $/ \mathrm{min} / \mathrm{mg}$ pancreatic enzyme. An adverse effect of this management is raising plasma levels of cholesterol and triglycerides, at least in rabbits, confirmed in our LPD plus pancreatin group, and therefore it should be used with caution in patients with lipid profile disorders. The exocrine pancreatic failure was observed in 6 rabbits (LPD positive control) that did not have supplementary pancreatic enzymes after LPD, which was clear for the development of a Wernicke-Korsakoff encephalopathylike process.

Cavallini et al. [27] reported pancreatic duct occlusion using a fibrin sealant in 6 consecutive patients with resectable periampullary or pancreatic carcinoma. Postoperative mortality was not observed. Nevertheless, pancreatic fistulae developed in 5 cases, but all spontaneously resolved in 1-4 months.

In most of the studies, patients were followed up even for 4 years. In our study, we followed up cases for 4 months, which according to the National Association of Family Rabbit Breeding (https://www.asnac.es/) corresponds to 12 years in humans. Overall, LPD without anastomosis of the pancreatic remnant significantly reduces perisurgical mortality and postoperative complications of PD. Marczell and Stierer [21] demonstrated satisfactory 
long-term results in humans (up to 3 postoperative years), which constituted an option during difficult operative circumstances [28]. Surgeon experience with one or the other pancreatic anastomosis technique seems to be the most important issue and not the technique itself [29]. Some studies reported that morbidity associated with LPD is higher than with anastomosis; therefore, LPD would only be considered as an alternative in difficult surgical situations [28]. Nevertheless, our results suggest that it is necessary to offer LPD the opportunity to be integrated as an option for PC surgery.

The use of this simple technique is suitable for geriatric patients, patients in poor condition, or patients with a serious trauma involving the pancreas when a shorter surgical time is mandatory. $\mathrm{DM}$ as a potential late problem has been suggested but is an infrequent complication.

\section{Acknowledgment}

We gratefully acknowledge Dr. Angeles Acevedo, Dean; the clinical laboratory, the surgical nursing staff, and the veterinarian from the Cristobal Colon University School of Medicine for their support, without which we would have not been able to carry out this study.

\section{Statement of Ethics}

The study was done in the Experimental Surgical Unit of the Cristobal Colon University School of Medicine following previous authorization by the Institutional Committee of Bioethics. All procedures were done with strict adherence to the Mexican official norms of technical specifications for experimentation on laboratory animals (NOM 062-ZOO-1999).

\section{Disclosure Statement}

The authors have no conflicts of interest to declare.

\section{Funding Sources}

None.

\section{Author Contributions}

Research concept and design: K.P.D. and E.S.-V.; collection and/or assembly of data: K.P.D.; E.M.; N.V./C.C.; and E.S.-V.; data analysis and interpretation: K.P.D.; E.M.; and E.S.-V.; writing or the article: K.P.D.; E.M.; N.V./C.C.; and E.S.-V.; critical revision of the article: K.P.D. and E.S.-V.; and final approval of the article: K.P.D.; E.M.; N.V./C.C.; and E.S.-V.

\section{References}

1 American Cancer Society. Cancer Facts \& Figures 2014 [accessed 2017 Jun 10]. Available from: http://www.cancer.org/acs/groups/ content/@research/documents/webcontent/ acspc-042151.pdf.

2 Kirkpatrick ID, Desser TS, Nino-Murcia M, Jeffrey RB. Small cystic lesions of the pancreas: clinical significance and findings at followup. Abdom Imaging. 2007 Jan-Feb;32(1): 119-25.

3 Parra-Herran CE, Garcia MT, Herrera L, Bejarano PA. Cystic lesions of the pancreas: clinical and pathologic review of cases in a five year period. JOP. 2010 Jul;11(4):358-64.

4 Ryan DP, Hong TS, Bardeesy N. Pancreatic adenocarcinoma. N Engl J Med. 2014 Sep; 371(11):1039-49.

5 Katabi N, Klimstra DS. Intraductal papillary mucinous neoplasms of the pancreas: clinical and pathological features and diagnostic approach. J Clin Pathol. 2008 Dec;61(12):1303-13.

6 DeWitt J, Devereaux B, Chriswell M, McGreevy $\mathrm{K}$, Howard $\mathrm{T}$, Imperiale $\mathrm{TF}$, et al. Comparison of endoscopic ultrasonography and multidetector computed tomography for detecting and staging pancreatic cancer. Ann Intern Med. 2004 Nov;141(10):753-63.

7 Hackert T, Büchler MW, Werner J. Current state of surgical management of pancreatic cancer. Cancers (Basel). 2011 Mar;3(1):1253-73.
8 Conway WC 2nd, Bolton JS. Surgical treatment of pancreatic cancer. J La State Med Soc. 2011 Mar-Apr;163(2):107-13.

9 Whipple AO, Parsons WB, Mullins CR. Treatment of carcinoma of the ampulla of Vater. Ann Surg. 1935 Oct;102(4):763-79.

10 Traverso LW, Longmire WP Jr. Preservation of the pylorus in pancreaticoduodenectomy. Surg Gynecol Obstet. 1978 Jun;146(6):95962.

11 Giudici F, Pesi B, Zambonin D, Scaringi S, Bechi P, Batignani G. Safer intestinal invagination for a solid pancreatico-jejunal anastomosis in presence of a soft texture pancreatic remnant and non-dilated duct. Hepatobiliary Pancreat Dis Int. 2016 Jun;15(3):324-8.

12 Brunschwig A. Pancreatoduodenectomy: a curative operation for malignant neoplasms in the pancreatoduodenal region; report of three over-five-year survivors. Ann Surg. 1952 Oct;136(4):610-24.

13 Goldsmith HS, Ghosh BC, Huvos AG. Ligation versus implantation of the pancreatic duct after pancreaticoduodenectomy. Surg Gynecol Obstet. 1971 Jan;132(1):87-92.

14 Tran K, Van Eijck C, Di Carlo V, Hop WC, Zerbi A, Balzano G, et al. Occlusion of the pancreatic duct versus pancreaticojejunostomy: a prospective randomized trial. Ann Surg. 2002 Oct;236(4):422-8.
15 Tersigni R, Capaldi M, Ialongo P, Grillo LR, Anselmo A. Surgical treatment of the pancreatic stump: preventive strategies of pancreatic fistula after pancreatoduodenectomy for cancer. G Chir. 2014 Sep-Oct;35(9-10):213-22.

16 Maciver A, McCall M, Mihalicz D, Al-Adra D, Pawlick R, Shapiro AM. The use of bovine pericardial buttress on linear stapler fails to reduce pancreatic fistula incidence in a porcine pancreatic transection model. HPB Surg. 2011;2011:624060.

17 Dindo D, Demartines N, Clavien PA. Classification of surgical complications: a new proposal with evaluation in a cohort of $6336 \mathrm{pa}-$ tients and results of a survey. Ann Surg. 2004 Aug;240(2):205-13.

18 Clavien PA, Barkun J, de Oliveira ML, Vauthey JN, Dindo D, Schulick RD, et al. The Clavien-Dindo classification of surgical complications: five-year experience. Ann Surg. 2009 Aug;250(2):187-96.

19 Nakase A, Matsumoto Y, Uchida K, Honjo I. Surgical treatment of cancer of the pancreas and the periampullary region: cumulative results in 57 institutions in Japan. Ann Surg. 1977 Jan; 185(1):52-7.

20 Nomikos IN, Farmakis N, Zizi A, Perrakis N, Datsis C, Vamvakopoulos NC. Reevaluating pancreatic duct ligation in Whipple procedure. J BUON. 2007 Oct-Dec;12(4):535-8. 
21 Marczell AP, Stierer M. Partial pancreaticoduodenectomy (Whipple procedure) for pancreatic malignancy: occlusion of a non-anastomosed pancreatic stump with fibrin sealant. HPB Surg. 1992 Jun;5(4):251-9.

22 Gentilello LM, Cortes V, Buechter KJ, Gomez GA, Castro M, Zeppa R. Whipple procedure for trauma: is duct ligation a safe alternative to pancreaticojejunostomy? J Trauma. 1991 May;31(5):661-7.

23 Idezuki Y, Goetz FC, Lillehei RC. Late effect of pancreatic duct ligation on beta cell function. Am J Surg. 1969 Jan;117(1):33-9.
24 Grossner D, von Kroge H, Berkhoff M, Klapdor R, Klöppel G. Insulinreserve und Morphologie des Pankreasschwanzes nach Pankreaskopfresektion bei unterschiedlichen Methoden der Versorgung. Langenbecks Arch Chir. 1989;374(1):4-11.

25 Soltani SM, O'Brien TD, Loganathan G, Bellin MD, Anazawa T, Tiwari M, et al. Severely fibrotic pancreases from young patients with chronic pancreatitis: evidence for a ductal origin of islet neogenesis. Acta Diabetol. 2013 Oct;50(5):807-14.

26 Hultquist GT, Karlsson U, Hallner AC. The regenerative capacity of the pancreas in ductligated rats. Exp Pathol (Jena). 1979;17(1): 44-52.
27 Cavallini M, Tallerini A, Stipa F. [Occlusion of the duct with a fibrin glue and preservation of the pylorus after resection of the duodenum and head of the pancreas for periampullary carcinoma]. Minerva Chir. 1991 Jul; 46(13-14):733-9. Italian.

28 Fromm D, Schwarz K. Ligation of the pancreatic duct during difficult operative circumstances. J Am Coll Surg. 2003 Dec;197(6): 943-8.

29 Kleespies A, Albertsmeier M, Obeidat F, Seeliger H, Jauch KW, Bruns CJ. The challenge of pancreatic anastomosis. Langenbecks Arch Surg. 2008 Jul;393(4):459-71. 